\title{
La política de comercio exterior de China y sus implicaciones para las relaciones comerciales con México ${ }^{1}$
}

\section{Resumen}

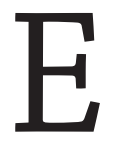

ste artículo analiza la estrategia de comercio exterior de China, diseñada e implementada en el contexto de la política de liberalización económica en la época post-maoísta; esto es, abarca el periodo del fin de la Guerra Fría al presente, cuando el contexto internacional estuvo marcado por la globalización económica y los ajustes al poder estratégico militar. El texto pone énfasis en la economía de China y su influencia en la estrategia de comercio exterior, tomando como referencia algunos aspectos sustanciales de la experiencia mexicana en estos mismos campos.

Palabras clave: China, México, liberalización económica, apertura comercial, comercio exterior

1. Artículo recibido el 20 de julio de 2011 y dictaminado el 9 de noviembre de 2011.

2. Profesor-investigador del Departamento de Estudios del Pacífico, Centro Universitario de Ciencias Sociales y Humanidades de la Universidad de Guadalajara, y miembro del sNi. El autor agradece el apoyo de la C. Lorena Velázquez en la actualización de la información estadística. 


\section{Abstract}

This paper analyzes the strategy of foreign trade of China, designed and implemented in the economic liberalization policy of the post-Maoist era. This policy was developed in the framework of economic globalization and worldwide strategic military power after the Cold War to the present. The text emphasizes the economic policy of China and its influence over foreign trade strategy, with reference to some substantial aspects of the Mexican experience in these fields

Keywords: China, Mexico, liberalization, openness, commercial relations, foreign trade.

\section{Introducción}

A partir del 12 de diciembre de 2011 las relaciones comerciales entre México y China han entrado en una nueva fase. Las medidas compensatorias impuestas por México a China en 2001 a un número importante de productos han expirado, lo cual implica que las reglas de operación de la Organización Mundial de Comercio (OMC) serán desde ahora las que regulen la relación comercial entre ambos países, incluyendo las disputas en los casos que cualquiera de ellos demuestre la afectación de cualquier sector productivo por prácticas desleales de comercio.

Para comprender cabalmente las razones que motivaron a los líderes de China a diseñar y poner en práctica las políticas de apertura económica, que incluyen el reajuste de las estructuras productivas y comerciales, hay que tener en cuenta que en los últimos lustros el ritmo del proceso de globalización se ha incrementado dramáticamente. El Estado y el mercado han propiciado las condiciones del cambio sin precedentes en las comunicaciones, transporte y tecnología de la información, por lo que el mundo es ahora mucho más interdependiente. El régimen internacional de comercio, sustentado en los principios y las reglas del desarrollo capitalista, tiene como corolario fundamental la liberalización económica y la apertura comercial.

Desde el punto de vista de México, la apertura comercial de China se ha visto reflejada en la lucha por el mercado de Estados Unidos y la "invasión" de productos chinos dentro del mercado mexicano. Para explicar esta circunstancia se plantean los siguientes objetivos: definir las similitudes y diferencias del proceso de integración de las economías de China y México en el contexto 
económico internacional, analizar la política de comercio exterior de China y las razones de las disputas comerciales con México y señalar los mecanismos a través de los cuales los dirigentes de ambos países han intentado resolver las disputas comerciales. Para lograr lo anterior se parte de datos duros y mediante argumentaciones teóricas de la economía política internacional (IPE), y dentro de ésta, de la teoría de la elección pública y la nueva división internacional del trabajo (NDIT).

\section{Políticas de apertura y comercio exterior de China y México}

No obstante las diferencias económicas políticas y sociales, China y México comparten esfuerzos similares de proteccionismo y liberalización económica. El más reciente (y de interés para este trabajo) abarca de los años ochenta del siglo XX hasta el presente. Estas políticas son similares en cuanto a amplitud y profundidad, pero muy diferentes en lo relacionado con su manejo. En términos generales, la estrategia de globalización de México se apega rigurosamente al Consenso de Washington, mientras que el proceso de globalización de China se ha dado de manera más gradual y bajo control gubernamental (Gallagher, 2008).

Pekín comenzó su proceso de apertura política y económica en 1971 con la visita de Nixon a China. Aunque en un principio la razón del acercamiento de China con EU correspondió más a un movimiento estratégico en la búsqueda de un nuevo equilibrio geopolítico global con énfasis en la relación tripartita EU-China-URSS, los efectos se reflejaron inmediatamente en sus relaciones comerciales con el exterior, sobre todo con Japón y varios países europeos. En este sentido, China emprendió un proceso de liberalización económica más de una década antes del colapso del Muro de Berlín (Jiang, 2008: 30). Una vez que las fuerzas de mercado comenzaron a desempeñar un papel más importante en el desarrollo económico de China, e integrarse a la economía global, el nivel de vida de la población comenzó a elevarse. La dirigencia china comprendió, además, que su programa de liberalización económica dependía de un ambiente internacional pacífico y estable en la era de la posguerra fría, y reconoció la necesidad de ajustar su política exterior hacia ese fin.

Las reformas comenzaron en China en el sector agrícola, revirtiendo el proceso de colectivización llevado a cabo durante la era maoísta. Más tarde, se extendieron a la liberalización de precios y la descentralización fiscal. Como parte de la reforma económica, a las empresas comerciales del Estado se les 
otorgó una mayor independencia administrativa. Esto propició la creación de varios tipos de corporaciones privadas dentro de los sectores industriales y de servicios. El sistema bancario también fue diversificado, incluyendo la creación y rápido desarrollo de las bolsas.

Es evidente que la política de liberalización económica de China ha generado tanto el crecimiento económico como la polarización económica entre clases sociales y entre las áreas rurales y urbanas. Sin embargo, China hoy día es la segunda economía del mundo, sólo después de los Estados Unidos. Durante los últimos treinta años las tasa de crecimiento económico anual ha sido de alrededor de 10\%. Como consecuencia de ello, en 2011 China se ha convertido en el principal productor y exportador de bienes a nivel mundial, incluso por encima de Estado Unidos, además de colocarse como el tercer importador de mercancías del mundo. De tal forma que, para el año 2011, el producto interno bruto (PIB) de China, medido en términos de paridad de poder de compra (PPP), fue de $\$ 11,316.24$ miles de millones de dólares, ${ }^{3}$ ocupando el tercer lugar mundial, mientras que el PIB per cápita fue de 5,183.86 dólares corrientes, equivalente a 8,294.07 dólares en términos de PPP (World Economic Outlook, 2011).

México, por su parte, desde los años ochenta, ha sido un ejemplo de la aplicación del modelo de reestructuración económica orientada por las reglas del mercado, así como de las limitaciones asociadas con este modelo. En el caso de México, el detonador del cambio en la política económica fue la crisis de la deuda de 1982 y el aparente agotamiento del modelo de industrialización basado en la substitución de importaciones. Desde entonces, los sucesivos gobiernos han hecho a un lado las políticas de desarrollo dirigidas por el Estado, orientadas esencialmente al desarrollo interno. En su lugar se adoptaron políticas de liberalización comercial, desregulación de la inversión extranjera directa y de los mercados financieros, además de la agresiva privatización de las empresas estatales. El ritmo y la extensión del proceso de reforma hicieron de México un caso paradigmático de la liberalización económica sin control estatal (Middlebrook y Zepeda, 2003: 3).

Como resultado de la apertura comercial, México surgió como un exportador importante de productos manufacturados; sin embargo, esto no se tradujo (como fue el caso de China) en un crecimiento económico. En cambio, la ampliación del comercio exterior y la inversión extranjera aumen-

3. A lo largo del trabajo me referiré a dólares, como dólares de EU. 
taron considerablemente la vulnerabilidad de la economía mexicana frente a los impactos externos. Hasta ahora la aplicación de un modelo económico neoliberal no ha sido capaz de lograr un crecimiento económico sostenido y suficiente, ni de propiciar un desarrollo socioeconómico equitativo.

En síntesis, la aplicación de políticas de apertura y liberalización económica ha reportado resultados diferentes para México y China. Una de las diferencias más sobresalientes es la del crecimiento del PIB. De acuerdo con datos de Banco Mundial, mientras China consiguió un crecimiento anual promedio de 9\% de 1981 a 2010, el aumento en México fue de sólo 3.2\%. Este hecho se manifiesta claramente en la tabla 1, que cubre los diez años que transcurren de 2001 a 2010. Otros indicadores importantes que explican las diferencias en el comportamiento del PIB entre China y México es el de la Formación Bruta de Capital (que en el caso de China fue $80 \%$ superior al de México en la década de 2001 a 2010). En cuanto al crecimiento de la inversión directa extranjera y la acumulación de reservas monetarias totales, las diferencias también son muy significativas.

Esta estructura económica muy asimétrica que comparten China y México es el resultado de las estrategias de liberalización y apertura económica, así como de la falta de atención del Estado para evitar o mitigar tales diferencias.

De lo anterior se deduce que no obstante las diferencias en el sistema político, en la estructura económica y en el proyecto de nación de sus dirigentes, la incorporación de ambos países a los procesos de globalización han incidido en la competitividad de sus economías incidiendo en la lucha por algunos mercados clave, incluyendo para el caso de México la disputa por su mercado interno.

Las políticas comerciales implementadas por China se basan en un enérgico nacionalismo, con un proyecto claramente definido de convertirse en una gran potencia. México por su parte, después de la apertura unilateral, con magros resultados, ha tratado de proteger su economía interna de fuerzas externas respondiendo más de manera casuística que a un proyecto de largo plazo.

En los últimos años, dada la situación del sistema económico internacional, México ha tenido una actitud de inmovilidad en la toma de decisiones. Los tomadores de decisiones, entre los que se cuentan los funcionarios públicos, los grandes empresarios y otros grupos de interés, como los sindicatos, han dificultado la definición de futuras estrategias de cambio estructural. El proceso de liberalización en sectores como la petroquímica, la electricidad y 


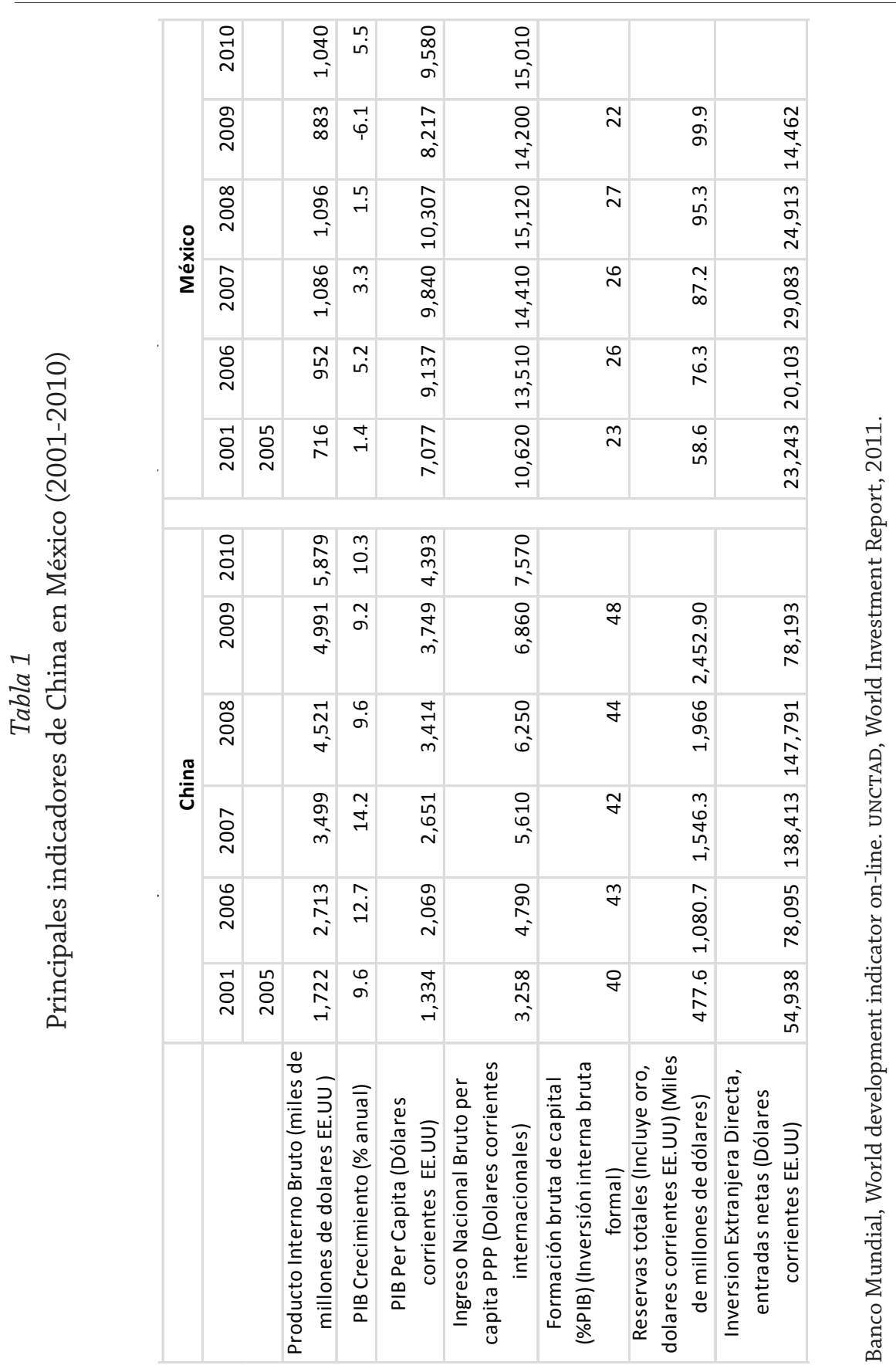


el sistema laboral, se han detenido, lo mismo que las reformas generales del sector público. La desregulación indiscriminada ha dado lugar a la formación de estructuras monopólicas en sectores como las telecomunicaciones y las finanzas. La inversión en desarrollo tecnológico, la productividad, la reinversión de excedentes y la formación de capital humano han sido insuficientes, de tal forma que la industria manufacturera orientada a la exportación no ha propiciado la expansión de las cadenas productivas, en especial de las grandes empresas exportadoras hacia las pequeñas y medianas empresas. Un elemento adicional es la falta de recursos financieros para actividades productivas $y$ las altas tasa de interés que ofrece el sistema financiero (Dussel, 2009: 285-294).

Por otra parte, una coincidencia entre China y México es la gran polarización de los ingresos familiares. La política de crecimiento económico a cualquier costo, establecida por los líderes de China, generó una gran disparidad económica, la cual se refleja en el coeficiente de Gini. Según el Informe sobre Desarrollo Humano en 2010, de las Naciones Unidas, la economía de China reportó un valor de 46.9 y México de 51.6 en dicho coeficiente. ${ }^{4}$

\section{El comercio exterior de China}

Por más de dos mil años las relaciones de China con el exterior han experimentado largos periodos de reclusión y apertura. La etapa más reciente de

4. En el coeficiente de Gini, un valor de 0 representa la igualdad absoluta y un valor de 100 la desigualdad absoluta. 
aislamiento ocurrió durante los primeros treinta años de la República Popular, cuando el país vivió un régimen económico semi-autárquico, caracterizado por la muy escasa relación comercial con Occidente. Durante este periodo su participación en el comercio mundial disminuyó significativamente y la inversión extranjera directa no se permitió. Los recursos destinados a la inversión fueron acotados por las directrices y las regulaciones gubernamentales. Las fuerzas del mercado desempeñaron un papel insignificante. Por lo tanto, se presentaron ineficiencias en el proceso de producción (como lo demuestra la masiva inversión en inventarios) y el abandono de la producción de bienes destinados al consumo básico de la población (Madison, 2007: 18).

La etapa de apertura iniciada en los años setenta - y que se mantiene hasta la actualidad - ha sido uno de los elementos característicos de las relaciones exteriores de la China actual. De este modo, en los últimos veinte años, China ha surgido como una fuerza importante en el comercio internacional, especialmente de productos manufacturados. Su enorme mercado, la gran oferta de mano de obra barata y la competitividad creciente, han atraído grandes cantidades de inversión extranjera, que ha propiciado el aumento espectacular de las exportaciones e importaciones de China. A su vez, la participación de China en el comercio mundial ha influido significativamente en la estructura del mismo (Lenz, 2003).

El crecimiento del comercio exterior de China en los últimos treinta años ha sido impresionante. De 1980 a 2010, aumentó de Us $\$ 38.1$ mil millones a Us $\$ 2.97$ billones. Y en los últimos diez años ha obtenido un superávit promedio anual de 133 mil millones de dólares. Sólo en 2010 el comercio exterior de China alcanzó los US $\$ 2.97$ billones, superior en un tercio al nivel de 2009, cuando había tenido una importante disminución debido a la crisis económica mundial de 2008-2009. En 2010, las exportaciones chinas crecieron en $31.1 \%$, mientras que las importaciones crecieron en $38.7 \%$. El crecimiento global fue de $34.7 \%$ (gráfica 1).

China es actualmente el mayor exportador mundial y el tercer importador. Sus principales socios comerciales son EU, Japón, Hong Kong, Corea del Sur, Taiwán y Alemania, los cuales representan más de 50\% del comercio internacional del país. En 2010, la Unión Europea continúo siendo el principal socio comercial de China. El comercio entre China y la Unión Europea creció en $31.8 \%$ en 2011 en relación con el año anterior hasta alcanzar los 479.71 miles de millones de dólares. El comercio con los Estados Unidos aumentó 


\section{Gráfica 1}

Comercio exterior de China (1978-2010)

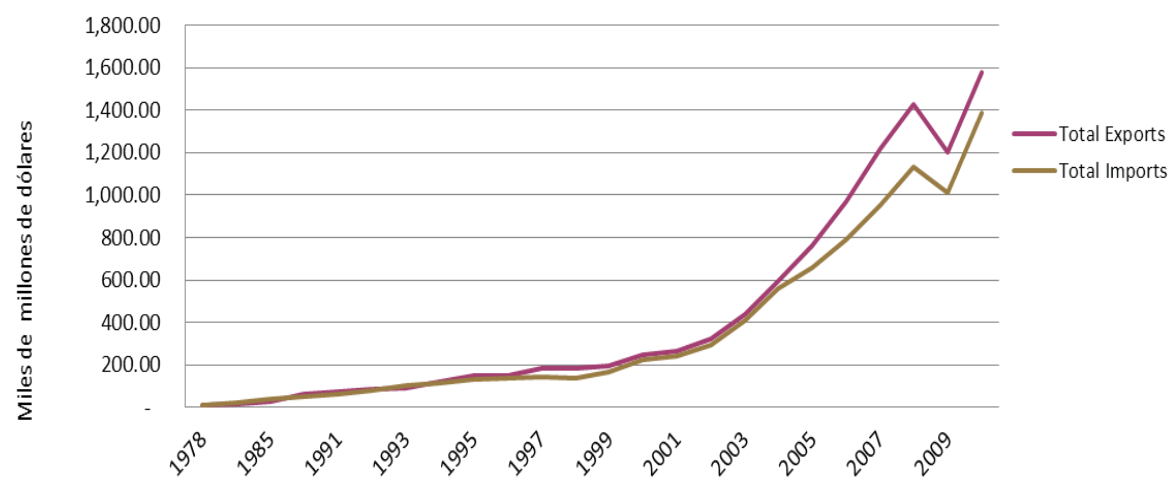

Fuente: para 1978-2008: China Statistical Yearbook 2009, disponible en: http//www.stats.gov. cn/tjsj/ndsj/2009/indexeh.htm, fecha de consulta: 03 de marzo de 2011. Para 2009: www.chinaview.cn, fecha de consulta: marzo 12. Para 2011: http://news.xihuanet.com/ english/2010-01/10/content 12784996.htm.

29.2\% anual y alcanzó los 385.34 mil millones de dólares, mientras que el comercio entre China y Japón aumentó 30.2\% para sumar 297.77 mil millones de dólares. El comercio entre China y la Asociación de Naciones del Sudeste Asiático (ASEAN) aumentó en 37.5\%, para sumar 292.78 mil millones de dólares (China Economía, 2011).

El cambio en la estructura de producción de China se refleja en su comercio exterior. Por lo tanto, la expansión comercial de China se ha logrado casi en su totalidad con productos manufacturados; así, $88.6 \%$ de sus exportaciones fueron de manufacturas, por encima del 71.4\% de 1990 (Lenz, 2003). En 2008, como se muestra en la siguiente tabla, $94.5 \%$ de sus exportaciones fueron productos manufacturados y sólo $5.5 \%$, productos básicos. En cuanto a las importaciones, $68 \%$ fueron manufacturas y el restante $32 \%$, productos primarios.

Por otra parte, la dirección del comercio de China ha cambiado significativamente. China se ha convertido en un socio cada vez más importante para los demás países asiáticos. Ahora funciona como una plataforma de producción en el proceso de ensamblaje final para un gran número de productos, incluyendo bienes con tecnología y diseño de países europeos y EU. Una gran cantidad de bienes, una vez convertidos en productos de consumo, son exportados a 
Tabla 2

China valor total de la Importaciones y Exportaciones, 2004-2008 (miles de millones de dólares EU)

\begin{tabular}{lrrrrr}
\hline & \multicolumn{1}{c}{2004} & \multicolumn{1}{c}{2005} & \multicolumn{1}{c}{2006} & \multicolumn{1}{c}{2007} & \multicolumn{1}{c}{2008} \\
\hline Valor Total de las importaciones & $1,154.60$ & $1,421.90$ & $1,760.40$ & $2,173.70$ & $2,563.30$ \\
y exportaciones & & & & & \\
Exportaciones Totales & 593.30 & 762.00 & 968.90 & $1,217.80$ & $1,430.70$ \\
Bienes Primarios & 40.60 & 49.00 & 52.90 & 61.50 & 78.00 \\
Bienes Manufacturados & 552.80 & 712.90 & 916.00 & $1,156.30$ & $1,352.70$ \\
Importaciones Totales & 561.20 & 660.00 & 791.50 & 956.00 & $1,132.60$ \\
Bienes Primarios & 117.30 & 147.70 & 187.10 & 243.10 & 362.40 \\
Bienes Manufacturados & 444.00 & 512.20 & 604.30 & 712.90 & 770.20 \\
Balance & 32.10 & 102.00 & 177.50 & 261.80 & 298.10 \\
\hline
\end{tabular}

Fuente: China Statistical Yearbook 2009. Disponible en: http://www.stats.gov.cn/tjsj/ ndsj/2009/indexeh.htm. Fecha de consulta: 03 de marzo de 2011.

los mercados internacionales como "productos chinos". Así, dentro de esta dinámica comercial, el déficit en la balanza comercial que China reporta con Asia, es compensado ampliamente con el superávit alcanzado en su relación con los países desarrollados y en desarrollo, incluido México. Las principales exportaciones de los socios y las importaciones reportadas por fuentes oficiales se muestran en la tabla 3.

De acuerdo con el People's Daily Online (2011), en 2010 la Unión Europea, los Estados Unidos y Japón continuaron siendo las fuente superavitarias más importantes para China. Además, el volumen de importaciones y exportaciones de las empresas privadas en 2010 aumentó más rápido que la media del país, hasta alcanzar 47\%. El máximo histórico alcanzado por las empresas es una señal de la recuperación lograda por China después de la crisis financiera global de 2008-2009.

Otra característica del comercio exterior de China son las ventajas que ha tenido para algunas regiones y países la apertura del mercado chino. Los países que se benefician de la expansión del comercio en China incluyen exportadores de capital, tecnología, materias primas y recursos naturales. Los países que se han especializado en la exportación de mano de obra intensiva, similares a los de China, como es el caso de México, han tenido una fuerte competencia con ese país en los mercados internacionales.

En la reconfiguración de la estructura económica de China, la inversión extranjera directa (IED) ha sido muy importante. Dicha IED es producto de las 
Tabla 3

Top de las exportaciones e importaciones chinas por destino, 2009 (miles de millones de dólares y porcentaje)

\begin{tabular}{llrlllr}
\hline Lugar & $\begin{array}{l}\text { Exportaciones } \\
\text { País }\end{array}$ & Valor & \multicolumn{1}{c}{ \% } & País & Valor & \multicolumn{1}{c}{$\%$} \\
\hline 1 & Estados Unidos & 220.8 & 18.4 & Japón & 130.9 & 13.0 \\
2 & Hong Kong & 166.2 & 13.9 & Corea del Sur & 102.6 & 10.2 \\
3 & Japón & 97.9 & 8.1 & Taiwán & 85.7 & 8.4 \\
4 & Corea del Sur & 53.7 & 8.1 & Estados Unidos & 77.4 & 7.7 \\
5 & Alemania & 49.9 & 4.5 & Alemania & 55.8 & 5.5 \\
6 & Países Bajos & 36.7 & 3.1 & Australia & 39.4 & 3.9 \\
7 & Reino Unido & $31 . .3$ & 2.6 & Malasia & 32.3 & 3.2 \\
8 & Singapur & 30.1 & 2.5 & Brasil & 28.3 & 2.8 \\
9 & India & 29.7 & 2.5 & Tailandia & 24.9 & 2.4 \\
10 & Australia & 20.6 & 1.7 & Arabia Saudita & 23.6 & 2.3 \\
\hline
\end{tabular}

Fuentes: PRC General Administration of Customs, China Customs Statistics, consultado el 15 de marzo de 2011. us-China Business Council.

reformas adoptadas por las autoridades chinas en los niveles nacional, regional y local (Prasad, 2004: 1). Así, de acuerdo con datos oficiales, la IED promedio de la década pasada (2001-2010) fue de 70.4 mil millones de dólares. Un nuevo estimulo para la IED fue el la adhesión de China a la OMC en diciembre de 2001 (Chinability, 2010).

La integración de China en la economía mundial ha contribuido al crecimiento sostenido del comercio internacional. En los últimos 20 años, tanto las exportaciones como las importaciones procedentes de China han crecido más rápido que el resto de las economías en todo el mundo. Como reflejo del crecimiento económico, China ha estado requiriendo del exterior grandes volúmenes de productos (materias primas y productos manufacturados), con los cuales han contribuido significativamente a mantener el crecimiento económico mundial, especialmente en los últimos años, cuando otras economías se han estancado o presentado crecimientos muy bajos. China también ha contribuido al fortalecimiento de los precios de los productos en todo el mundo; este país es actualmente el mayor importador de cobre y acero, y es uno de los grandes importadores de otras materias primas industriales como hierro y aluminio. 
En el ámbito de la política nacional algunos autores señalan que en China no existe una perspectiva única sobre cómo abordar la relación con las potencias extranjeras, incluyendo la negociación y firma de tratados comerciales. En este sentido, los intereses burocráticos han influido con más frecuencia en el proceso de toma de decisiones. Los intereses proteccionistas a nivel ministerial, incluyendo no sólo las que tradicionalmente han contado con el apoyo del Estado chino, sino también los encargados de la supervisión de las industrias emergentes de China, han expresado su oposición a las ofertas de liberalización comercial. La oposición de una amplia gama de actores burocráticos se ha convertido en un factor de estancamiento o retraso en las negociaciones comerciales (Zeng, 2007: 14; Zeng y Mertha, 2007: 13)

Las predicciones sobre el comportamiento de China, basadas en un supuesto de que existe un frente monolítico, sin tomar en cuenta la variedad de actores en la definición de las políticas nacionales, puede llevar a errores de apreciación política. Al tratar con China es necesario tomar en cuenta la importancia relativa de las fuerzas políticas que influyen en la conformación de la trayectoria del país dentro del sistema mundial de comercio (Zeng, 2007: 13-16).

\section{El comercio entre México y China}

En este apartado se analizan las relaciones comerciales de los últimos decenios entre México y China. Aunque cabe señalar que las relaciones comerciales entre la República Popular China (RPCh) y nuestro país se iniciaron inmediatamente después del establecimiento de relaciones diplomáticas en 1972, durante los primeros años del nuevo régimen el comercio directo fue exiguo y esporádico, centrado en algunos productos agrícolas e insumos industriales

Sin embargo, desde los años ochenta, el comercio entre México y China ha tenido un crecimiento sin precedentes. Como se muestra en la siguiente tabla, el comercio total pasó de 43.1 mil millones en 1993 a 49.805 mil millones de dólares en 2010, lo cual representa un crecimiento anual promedio de $14.4 \%$. Este aumento constante sólo se vio opacado en 2009, como resultado de la crisis económica mundial de 2008-2010. En 2009 el valor de las mercancías intercambiada bajó en 5.6\%; sin embargo se dio un repunte de $43.3 \%$ al siguiente año. Las exportaciones de México a China aumentaron $89.4 \%$ de 2009 a 2010, mientras que las importaciones crecieron 40.2\%. No obstante, el crecimiento en el déficit para México fue de $36.6 \%$. 


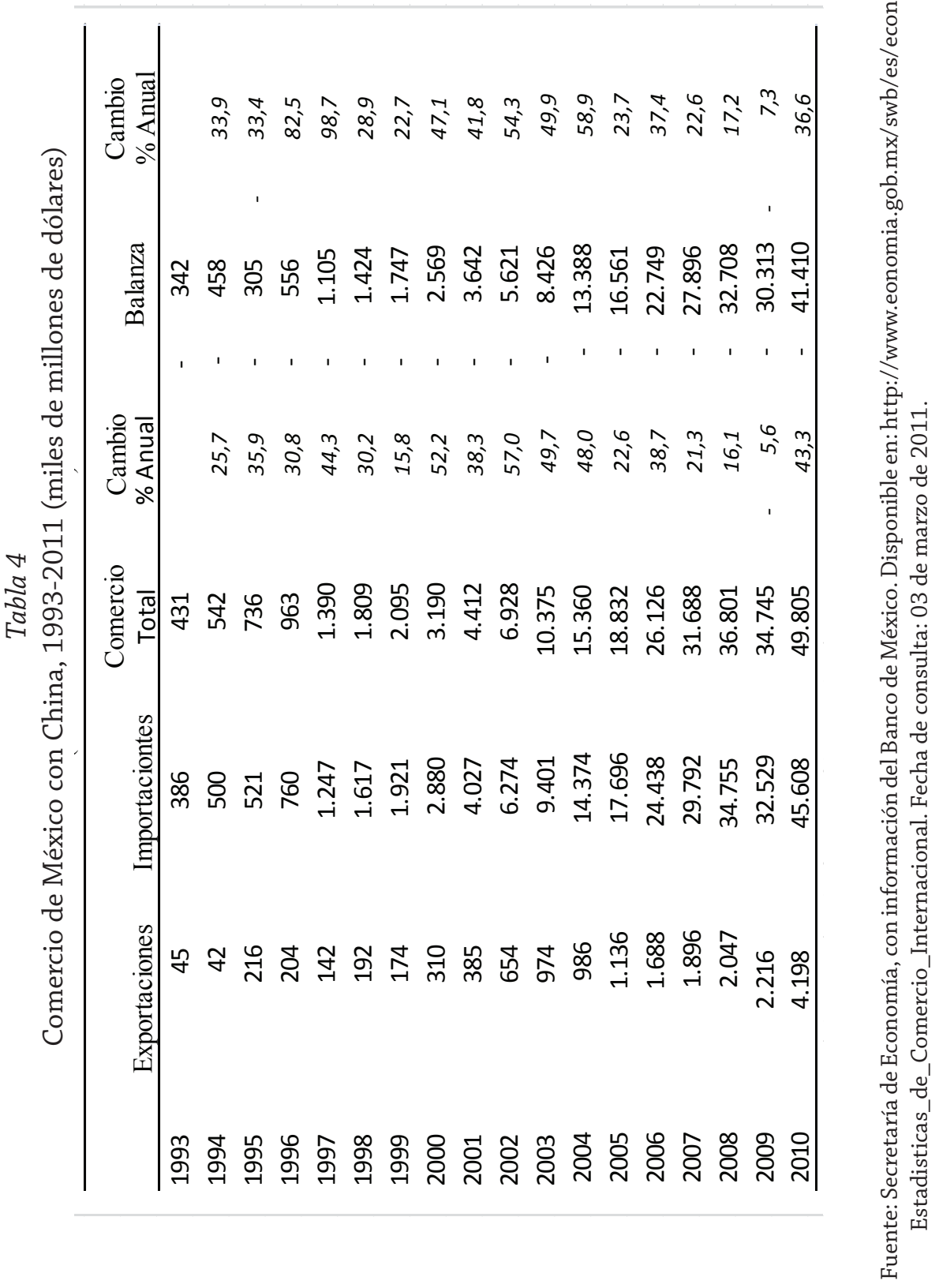


Cabe señalar que hay una gran diferencia en las cifras de comercio bilateral reportados por China y México, tal como se muestra en la tabla 4. Sólo en 2008, México registró un déficit 32,708 millones de dólares, mientras que para China el déficit de México fue de sólo 10,172 millones de dólares (tabla 5). Las grandes diferencias de datos son resultado de la metodología de recopilación de información estadística de cada país (Promexico, 2010; Dussel, 2005: 50-61).

\section{Tabla 5}

Comercio exterior de China con México, 1994-2008 (millones de dólares)

\begin{tabular}{rrrrr}
\hline Año & Exportaciones & Importaciones & Total & Balanza \\
\hline 1994 & 201.5 & 93.9 & 295.3 & 107.6 \\
1995 & 195.1 & 194.5 & 389.6 & 0.6 \\
1996 & 221.1 & 297.2 & 518.3 & 76.1 \\
1997 & 413.7 & 184.3 & 598.0 & 229.4 \\
1998 & 836.8 & 689.3 & 147.5 & 147.5 \\
1999 & 791.7 & 159.3 & 950.9 & 632.4 \\
2000 & $1,335.3$ & 488.3 & $1,823.5$ & 847.0 \\
2001 & $1,790.4$ & 761.1 & $2,551.5$ & $1,029.3$ \\
2002 & $2,863.7$ & $1,115.0$ & $3,978.6$ & $1,748.7$ \\
2003 & $3,267.0$ & $1,676.7$ & $4,943.8$ & $1,590.3$ \\
2004 & $4,972.8$ & $2,139.8$ & $7,112.6$ & $2,832.9$ \\
2005 & $5,537.7$ & $2,225.3$ & $7,763.0$ & $3,312.4$ \\
2006 & $8,823.6$ & $2,607.1$ & $11,430.7$ & $6,216.5$ \\
2007 & $11,706.1$ & $3,263.3$ & $14,969.4$ & $8,442.8$ \\
2008 & $13,866.5$ & $3,690.3$ & $17,556.7$ & $10,176.2$ \\
\hline
\end{tabular}

Fuente: China Statistical Yearbook, compilado por National Bureau of Statistics of China, 1996-2008. Disponible en: http://www.stats.gov.cn/english/statisticaldata/yearlydata. Fecha de consulta: 09 de marzo de 2011.

La razón fundamental del rápido aumento del comercio entre China y México es la aplicación por parte de ambos países de una política económica de apertura comercial y de liberalización económica. Además, el proceso de globalización en el cual se insertan estas políticas les ha asignado funciones específicas dentro de la división internacional del trabajo. De ahí que los sectores fundamentales de las economías de ambos países coincidan en las etapas media o final de los procesos productivos globales, que han provocado la lucha por mercados de consumo. 
Los instrumentos funcionales que configuran la integración regional y global son los organismos multilaterales creados expresamente dentro de los regímenes de comercio y finanzas. De esta forma los flujos de comercio y de capital delinean la estructura de producción nacional, balanza de pagos, transferencia de tecnología, competitividad, empleo y medio ambiente.

Desde la década de 1990, China y México han hecho progresos sustanciales en su comercio exterior. De 1990 a 2010, con una tasa media de crecimiento anual de $18.3 \%$, China se ha convertido en el más grande exportador de mercancías del mundo al alcanzar en 2010 un valor de 2.970 billones de dólares. El comercio exterior de México, por su parte, con un incremento anual de $11.3 \%$ durante los últimos 17 años, pasó de 99.4 mil millones de dólares en 1993 a 542.5 mil millones de dólares en 2010, ocupando así el decimoquinto lugar mundial.

El comercio entre China y México se caracteriza por su enfoque en pocos productos. Las principales exportaciones de China a México incluyen equipos eléctricos, electrónicos, de audio y video (y piezas de repuesto), mecánicos (y piezas de repuesto), así como juguetes, productos de caza, de óptica, equipo fotográfico médico y productos de plástico. Por su parte, las importaciones chinas desde México incluyen metales, minerales, equipo electromecánico y de transporte, plástico, caucho, productos químicos y productos de cuero.

El comercio bilateral entre China y México tiene otras características importantes. En primer lugar, en los últimos 15 años (1996-2010) el comercio tuvo $37.63 \%$ de incremento anual, aunque al mismo tiempo el déficit de México aumentó en $41 \%$ anual, como se muestra en la tabla 4. De las exportaciones mexicanas a China, $25 \%$ se concentran en autopartes, seguido de varias materias primas como cobre, escoria de minerales, hierro, acero y aluminio; las cuales alcanzaron $37.4 \%$ en 2010. Las importaciones mexicanas de productos electrónicos y piezas automotrices representaron $69.0 \%$ en 2010 (tablas 6 y 7). Estos dos sectores son la principal fuente del déficit comercial de México con China. La estructura general del comercio exterior de México y China presenta importantes similitudes, las cuales - como se ha mencionado- definen el grado de competitividad comercial. Por ejemplo, entre las principales exportaciones de ambos países en 2010 están la electrónica y las autopartes. Estos dos sectores representaron $36.1 \%$ y $44.3 \%$ de las exportaciones chinas y mexicanas, respectivamente. Una diferencia entre las exportaciones de México y China son las exportaciones de automóviles, que para México representan $16.9 \%$ de sus exportaciones (454.2 mil millones de 
dólares), mientras que las exportaciones chinas de automóviles equivalen a $3.6 \%$ de sus exportaciones totales (48.5 mil millones de dólares) (tablas 6 y 7 ).

\section{Tabla 6}

México: principales productos de exportación a China (millones de dólares). Anual: enero-diciembre

\begin{tabular}{|c|c|c|c|c|c|c|c|c|}
\hline & \multirow[b]{2}{*}{ HS Descripción } & \multirow[b]{2}{*}{2007} & \multirow{2}{*}{$\frac{\text { Año }}{2008}$} & \multirow[b]{2}{*}{2009} & \multirow[b]{2}{*}{2007} & \multicolumn{2}{|c|}{ \% Participación } & \multirow{2}{*}{$\frac{\% \text { Cambio }}{\text { 09-ago }}$} \\
\hline & & & & & & 2008 & 2009 & \\
\hline & & $1,895,477$ & $2,046,912$ & $2,215,587$ & 0,7 & 0,7 & 0,97 & 8,24 \\
\hline 84 & $\begin{array}{c}\text { Reactores nucleares, boilers, } \\
\text { maquinaria mecanica }\end{array}$ & 362,653 & 477,195 & 522,933 & 15,2 & 23,3 & 25,0 & 15,9 \\
\hline 74 & Cobre ysus manufacturas & 360,942 & 487,244 & 408,177 & 19,0 & 23,8 & 18,4 & $-16,2$ \\
\hline 26 & Minerales de escoria y cenizas & 288,350 & 291,720 & 268,763 & 9,8 & 9,5 & 12,1 & 7,9 \\
\hline 87 & $\begin{array}{l}\text { Vehículos fe rroca rril y material } \\
\text { rodante del tranvía }\end{array}$ & 211,988 & 180,995 & 209,282 & 11,2 & 8,8 & 9,5 & 15,6 \\
\hline 85 & $\begin{array}{l}\text { Maquinaria electrica, } \\
\text { equipo,partes y } \\
\text { telecomunicaciones }\end{array}$ & 186,201 & 143,237 & 124,019 & 19,1 & 7,0 & 5,6 & 13,4 \\
\hline 29 & Quimicos Organicos & 135,378 & 58,544 & 121,703 & 2,2 & 2,9 & 5,5 & 107,9 \\
\hline 72 & Hierro y a cero & 50,579 & 50,887 & 109,215 & 2,7 & 2,5 & 4,9 & 114,6 \\
\hline 39 & $\begin{array}{l}\text { Platicos y articulos } \\
\text { relacionados }\end{array}$ & 41,544 & 94,738 & 93,517 & 7,1 & 4,6 & 4,2 & 1,3 \\
\hline 76 & $\begin{array}{l}\text { Aluminio y articulos } \\
\text { relacionados }\end{array}$ & 41,382 & 9,541 & 44,783 & 1,5 & 0,5 & 2,0 & 369,4 \\
\hline 52 & $\begin{array}{l}\text { Algodón, Hilados y tejidos de } \\
\text { los mismos }\end{array}$ & 38,607 & 42,361 & 43,157 & 2,2 & 2,1 & 2,0 & 1,9 \\
\hline & Suma & $1.717,623$ & $1.836,463$ & $1.975,550$ & & & & \\
\hline & Porcentaje del total & 90.6 & 89.7 & 89.2 & & & & \\
\hline
\end{tabular}

Fuente: World Trade Atlas, consultado el 10 de febrero de 2011.

Por otra parte, respecto a la demanda china de productos agrícolas, alimentos y bebidas, éstos son precisamente los rubros donde México presenta un creciente déficit comercial. Lo anterior es importante para México puesto que compite en el mercado internacional con China en estos sectores, al presentar ambos una elevada demanda de tales bienes. Asimismo, en el resto de los sectores (electrónica, auto-partes y automóviles) cada vez más se presenta un alto potencial de competencia directa entre China y México (Dussel, 1995: 18-21).

Es importante destacar además que las exportaciones mexicanas dependen en gran medida de los insumos y de las empresas extranjeras. Así, 78.02\% de las exportaciones mexicanas en el periodo de 1993 a 2004 dependía de las importaciones temporales que eran re-exportadas como productos o intermedios. Esta estructura comercial refleja el bajo nivel de valor agregado na- 
La política de comercio exterior de China y sus implicaciones para las relaciones comerciales

\section{Tabla 7}

México: principales productos de importación de China (2007-2009)

\begin{tabular}{|c|c|c|c|c|c|c|c|c|}
\hline & & & Año & & & $\begin{array}{c}\% \\
\begin{array}{c}\text { Participa } \\
\text { ción }\end{array} \\
\end{array}$ & & $\%$ Cambio \\
\hline & HS Descripción & 2007 & 2008 & 2009 & 2007 & 2008 & 2009 & $09 / 08$ \\
\hline & & $29.746,81$ & $34.754,28$ & $32.528,97$ & 10,55 & 11,25 & 13,9 & 6,4 \\
\hline 85 & $\begin{array}{l}\text { Maquinaria electrica, } \\
\text { equipo,partes y } \\
\text { telecomunicaciones }\end{array}$ & $12.915,44$ & $15.554,64$ & $15.361,47$ & 43,42 & 22,76 & 47,2 & 1,24 \\
\hline 84 & $\begin{array}{c}\text { Reactores nucleares, boilers y } \\
\text { maquinaria }\end{array}$ & $6.105,48$ & $6.713,60$ & $7.198,19$ & 20,53 & 19,32 & 22,1 & 7,23 \\
\hline 95 & $\begin{array}{l}\text { Jugetes, juegos, equipo de } \\
\text { deportes y accesorios }\end{array}$ & $2.099,08$ & $2.193,82$ & $1.610,19$ & 7,06 & 6,31 & 4,95 & 26,6 \\
\hline 90 & $\begin{array}{c}\text { Opticos, instrumentos medicos } \\
\text { y accesorios }\end{array}$ & $1.529,97$ & $1.671,82$ & $1.279,33$ & 5,14 & 4,81 & 3,39 & 23,48 \\
\hline 39 & $\begin{array}{l}\text { Platicos y articulos } \\
\text { relacionados }\end{array}$ & 737,11 & 883,83 & 775,97 & 2,48 & 2,54 & 2,39 & 12,2 \\
\hline 73 & Articulos de Hierro y acero & 475,75 & 672,00 & 659,49 & 1,6 & 1,93 & 2,03 & 1,86 \\
\hline 98 & $\begin{array}{l}\text { Agricolas, construcción, } \\
\text { electricos, gas, sanitarios }\end{array}$ & 544,76 & 658,35 & 587,36 & 1,83 & 1,89 & 1,81 & 10,78 \\
\hline 87 & $\begin{array}{l}\text { Vehículos fe rroca rril y material } \\
\text { rodante del tranvía }\end{array}$ & 653,78 & 786,29 & 537,48 & 2,2 & 2,26 & 1,65 & 31,64 \\
\hline 29 & Quimicos organicos & 314,01 & 458,49 & 478,60 & 1,06 & 1,32 & 1,47 & 4,39 \\
\hline \multirow[t]{3}{*}{94} & $\begin{array}{c}\text { Muebles, lamparas, } \\
\text { iluminación, ropa de cama, } \\
\text { cojines }\end{array}$ & 491,77 & 551,06 & 409,85 & 1,65 & 1,59 & 1,26 & 25,63 \\
\hline & Suma & $25.867,16$ & $30.143,70$ & $28.898,56$ & & & & \\
\hline & Porcentaje del total & 87.0 & 87.0 & 87.0 & & & & \\
\hline
\end{tabular}

Fuente: World Trade Atlas, consultado el 10 de febrero de 2011.

cional de las exportaciones y las dificultades de la manufactura mexicana para propiciar una balanza comercial positiva (Dussel, 1995: 21-23).

Es un hecho que la rápida expansión de China en el comercio mundial ha complicado la situación económica y comercial de México. En los últimos veinte años, su déficit comercial con China (y el Este de Asia) se ha incrementado significativamente. A pesar de que dicho déficit ha sido compensado por el superávit de México con otras regiones (especialmente en América del Norte), se ha creado una gran incertidumbre y temor entre varios sectores productivos de la economía mexicana, en particular aquellos que han perdido parte de sus mercados nacionales y extranjeros.

Para México, la balanza comercial desfavorable y el temor en varios sectores manufactureros con frecuencia se ha convertido en un tema político, el cual se ha extendido a la sociedad mexicana con la generación de una opinión 
pública adversa a los "productos chinos". En comparación con el resto de países de América Latina, México es el más vulnerable, con $97 \%$ de sus exportaciones de manufacturas (que representan $71 \%$ de la base de las exportaciones nacionales) bajo amenaza de China en 2009. En este momento, muchas de las principales industrias de exportación mexicanas, en particular los textiles, prendas de vestir y electrónica, pende de un hilo a causa de la competencia china (Gallagher, 2011).

El problema del déficit de México con China, y por extensión con la zona del Pacífico asiático, va más allá de las estrategias de comercialización de los gobiernos en el mercado mundial de bienes y servicios. Esto es, las empresas transnacionales (ETN) cada vez tienen un mayor margen de acción para actuar de acuerdo a sus propios intereses, los cuales pueden coincidir o no con los de las economías nacionales.

Una de las limitaciones que México enfrenta en el equilibrio de su comercio con China es la imposibilidad de venderle petróleo u otras materias primas, como es el caso de otros países de América Latina. Como señalaron Zha y Breslin (2010), para China la energía es una prioridad clara a medio y largo plazos, por lo cual ha aumentado su interés en América Latina y el Caribe con el fin de diversificar sus fuentes de abastecimiento.

Otra cuestión importante para las relaciones comerciales México-China es el punto de vista que las empresas y el gobierno de México tienen sobre el mercado chino y viceversa. Esto se refleja en el número y monto de la inversión en cada país. Según la Unidad de Inteligencia de Negocios de ProMéxico (2010), de 2000 a 2009, las principales empresas chinas que habían invertido en México fueron Huawei Technologies, Grupo Hentia Worldbest Group Co., Ltd, la Corporación zTE, el Grupo Huaxi, Grupo Lenovo, Grupo Jinchuan, Golden Dragon Precise cobre Pipe Co. y Hutchison Ports Holdings.

En total, a finales de 2009, 563 empresas con capital chino se habían registrado en México. Entre estas empresas la mayoría se dedican a actividades comerciales, como son los bienes diversos de temporada, joyería, regalos, productos para hogar y oficina, productos navideños, artículos de cuero, bombas de agua, motocicletas, bicicletas, generadores de energía, productos médicos, maquinaria, equipo y repuestos, maquinaria industrial y de telecomunicaciones. Las cifras de inversión no son exactas dado que muchas empresas realizan sus actividades a través de filiales en otros países.

Por su parte, las principales empresas mexicanas que han invertido en China son Ketcon, Corporación San Luis, Gruma, Bimbo, Softek y Grupo Alfa. 
Las relaciones comerciales más destacadas y productivas entre las empresas mexicanas y chinas son de marcas premium. En el caso de México, representadas por el Grupo FEMSA y Grupo Modelo, así como por Bimbo. La compañía de medios Televisa reportó casos de éxito de la traducción y transmisión de telenovelas mexicanas en China. Esta empresa reporta planes para producir en forma conjunta con la China International Television Corporation (CITVC) nuevas telenovelas. Está claro que la incursión de unas pocas empresas multinacionales mexicanas en el mercado chino no puede influir en la reducción de la desigualdad comercial entre ambos países.

El Ministerio de Relaciones Exteriores de China ha mencionado otros proyectos de cooperación con México, como son las inversiones del Grupo Lenovo y el Grupo de Jinlong de la provincia de Henan, el proyecto de la empresa filial de CNPC, que ganó la licitación de un proyecto de prospección geológica con Pemex por un valor de 140 millones de dólares. Sinopec Servicio, junto con una empresa estadounidense, llegó a un acuerdo sobre el desarrollo de campos abandonados de Pemex. El contrato por un valor de 1,000 millones, firmado por el China Development Bank y América Móvil de México se llevó a cabo sin problemas (MFA, 2010).

Otro tema de gran importancia para las relaciones entre China y México es la acción de las empresas transnacionales, las cuales tienen grandes inversiones en ambos países. Es bien sabido que las ET actúan como una herramienta eficaz en la reconfiguración de los recursos productivos y comerciales entre las diferentes áreas y regiones del mundo. Las ET también están involucradas en la integración de las economías de los países desarrollados con las economías en desarrollo y que influyen en la configuración de un nuevo sistema económico mundial

En este sentido el papel de las empresas transnacionales ha sido crucial para configurar la estructura de producción y definir los flujos de comercio internacional. Así, mientras que las ET construyen plantas productivas en China, al mismo tiempo pueden trasladar ciertas fases de la producción a Vietnam o subcontratar en México; aprovechar nuevas oportunidades en Costa Rica o la República Checa, y desarrollar una nueva aplicación en Israel. El mayor impacto en la obtención de utilidades en todo el mundo se refleja en la producción, el empleo, la investigación y el desarrollo (ID), así como las compras en los mercados (Moran, 2011).

En este contexto, las empresas chinas han estado atrayendo IED y asumiendo los retos que les imponen las empresas transnacionales. Esto 
incluye el uso de marcas y el posicionamiento en los mercados, así como la asimilación de tecnología avanzada y capacidades de gestión. Las empresas chinas nacionales y transnacionales están en continuo crecimiento en tamaño y fuerza para competir con las empresas trasnacionales extranjeras. Esta circunstancia está ayudando a ajustar a las empresas chinas para poner en práctica su plan estratégico de salir a competir en los mercados productivos y comerciales a nivel mundial.

\section{El comercio de México y China con los Estados Unidos}

La relación comercial de México y China con los Estados Unidos ha sido otra fuente de disputa entre los dos países, especialmente desde que China se integró a la OMC en 2001. De hecho, en los últimos 20 años, China y México han aumentado significativamente su comercio con EU y ambos han tenido éxito en términos de superávit comercial. Sin embargo, la velocidad de la participación de China en el mercado de eu ha sido muy superior a la de México y muchos productos chinos están desplazando a los de origen mexicano.

En los últimos 20 años (de 1990 a 2010) las importaciones de EU desde México y las exportaciones de Estados Unidos a México crecieron de manera casi paralela. De este modo, mientras que las importaciones de Estados Unidos del mercado mexicano crecieron a una tasa anual de $11.26 \%$, las exportaciones lo hicieron en 9.9\%; esto dio como resultado un aumento en el superávit comercial de México con los Estados Unidos, el cual pasó de 1.9 mil millones de dólares en 1990 hasta 66.3 mil millones de dólares en 2010.

Por su parte, las importaciones de EU desde China reportaron un aumento anual promedio de $17.69 \%$, y un incremento en las exportaciones de $16.41 \%$ anual. Esta diferencia entre las importaciones y las exportaciones significó que el superávit de 10.4 mil millones de EU en 1990, se convirtiera en un déficit de 273.1 mil millones en 2010 (tabla 8).

Esta información que se muestra en gráfica y la figura 3, presenta que inmediatamente después de 2001, cuando China ingresó a la OMC, desplazó a México del segundo lugar como socio comercial de EU. La misma información nos muestra que la cuota del mercado de Eu entre los dos países se ha mantenido casi constante. De la misma manera se puede ver que las fluctuaciones de las importaciones de Eu desde México y desde China son más o menos proporcionales, tal como se percibe en la disminución de las importaciones 


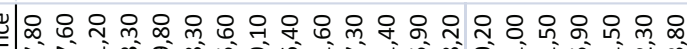

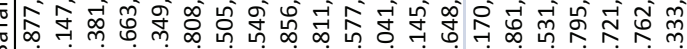

œ

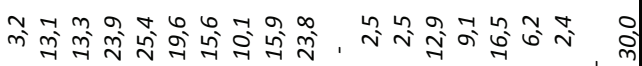

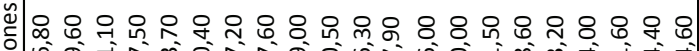

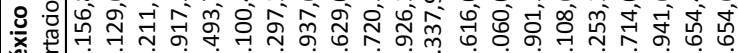

递

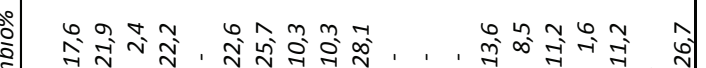

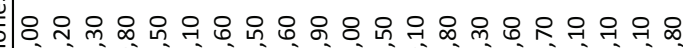

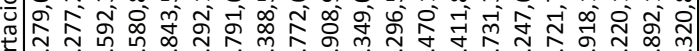

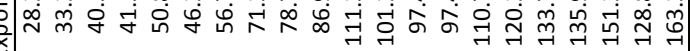

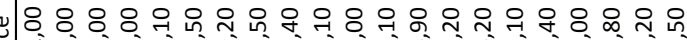

ণ্

ळ

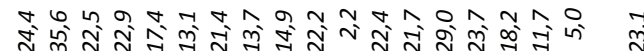

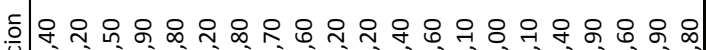

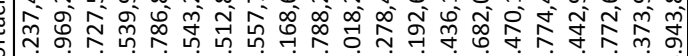
में

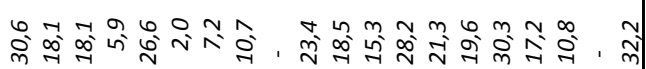

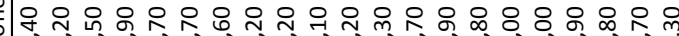

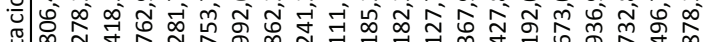
சம்

3

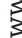

ํㅏㅁ

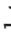

$\stackrel{0}{ }$

की

บั

政

:

氙

ต ช

동

营

灵

क

ด

䒕

दं

.ำ

永

क्ष

荧

.5ำ

닌

วิ

光

ค

जै

咨 Sু 
estadounidenses desde México y China durante la pasada crisis económica de 2008-2009 y la recuperación en 2010. Esto muestra también que, incluso ahora, hay un alto grado de convivencia entre las economías de China y México en el mercado de los Estados Unidos.

\section{Figura 3}

Comercio de Estados Unidos con México y China

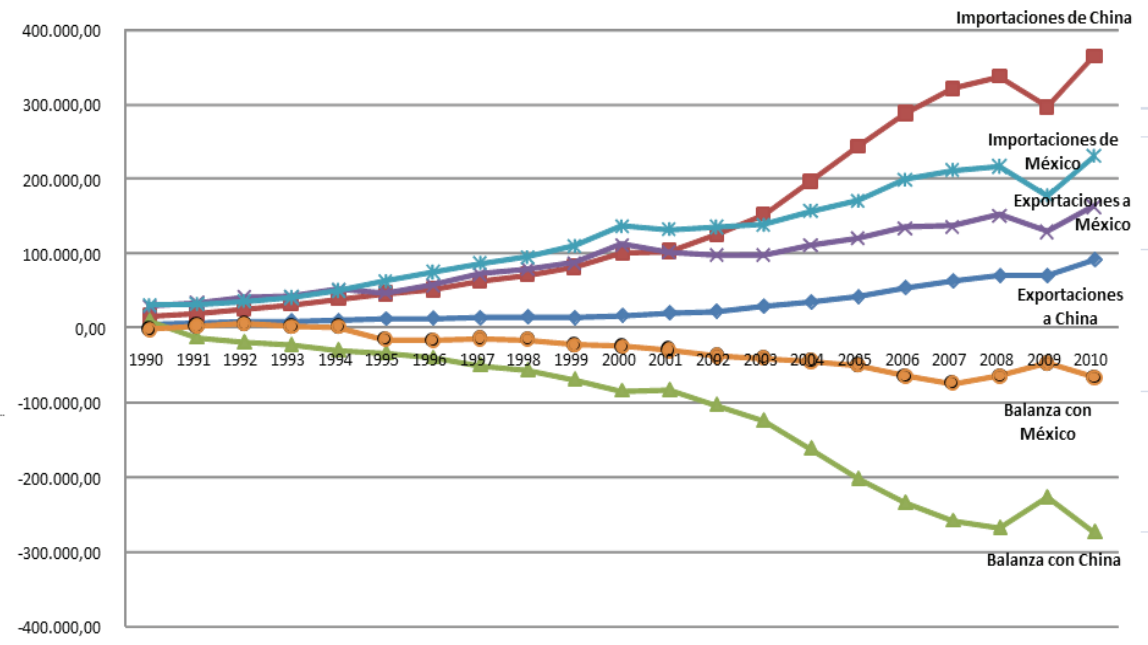

Fuente: US Census Bureau. Foreign Trade Division. Data Dissemination Branch, Washington DC. Disponible en: http://www.census.gov/foreigntrade/balance/c5700.html. Fecha de consulta: 04 de marzo de 2011.

La razón fundamental de que China marche a la vanguardia de México en el mercado de EU se debe al enfoque de ambos países sobre la globalización. México ha seguido una política de manos libres, mientras que China aplica una política de mayor control gubernamental. China lidera el mercado de los EU, a pesar de estar a 18 días de distancia para los buques de carga. El TLCAN asegura a México un mercado prácticamente sin aranceles, mientras que los aranceles a las exportaciones de China al mercado de EU casi alcanzan $6 \%$ (Gallagher 2008).

Con la adhesión de China a la OMC, la posición de México en el mercado de EU se vio afectada dada la similitud en la dotación de ambos países, así como sus políticas orientadas a la exportación (Dussel, 2005). En términos 
generales, ambos países se han especializado en electrónica, autopartes, juguetes, muebles, calzado y los bienes de la cadena productiva hilo-textilesconfección.

En cuanto a competitividad, China supera a México en competitividad global; sin embargo, México predomina en algunas ramas específicas. Como se muestra en la información estadística de las páginas anteriores (sobre todo en la tabla 8 y la gráfica 3), China y México comparten espacio en el mercado de Eu y el mundo. Sin embargo, contrariamente a las expectativas más optimistas respecto a que las ventajas competitivas de ambos países se ajustarían para evitar nuevos conflictos comerciales, esto no ha sido así. Los conflictos entre China y México han aumentado desde 2004. Los líderes de ambos países son conscientes de esta situación y para hacer frente a ella han tratado de resolver los problemas mediante el diálogo.

\section{El diálogo México-China sobre temas comerciales}

En los últimos años, uno de los temas más difíciles de las relaciones comerciales entre China y México ha sido la forma en que ambos países están llevando a cabo el proceso de liberalización económica. El punto central es que el flujo de mercancías chinas crece cada vez más en el mercado mexicano, no obstante las medidas proteccionistas establecidas por el gobierno de México.

En septiembre de 2001, como condición para que México diera su anuencia al ingreso de China a la OMC, ésta última acepto firmar un acuerdo bilateral especial, a través del cual otorgaba a México un periodo de gracia de seis años para mantener las medidas compensatorias en cientos de productos chinos. El periodo terminó en 2007, pero después de negociaciones adicionales, en noviembre de 2008 México y China firmaron un nuevo instrumento conocido como Acuerdo Transitorio sobre Medidas Correctivas Comerciales. A través de este instrumento se excluyeron 749 líneas arancelarias a los productos chinos que entran a México y se continúo con 204 fracciones arancelarias para los productos chinos más sensibles para la industria mexicana, sobre todo en sectores como el textil, calzado, ropa y juguetes

El nuevo acuerdo tuvo una vigencia de cuatro años. En éste, los aranceles oscilaron entre $60 \%$ y $35 \%$, con un proceso de desgravación paulatina hasta diciembre 12 de 2011, cuando llegaría a su fin, sin posibilidades de renovación. Los sectores industriales cubiertos fueron textiles, ropa, calzado, juguetes, bicicletas, motos, herramientas, electrodomésticos, maquinaria eléctrica, 
productos químicos, encendedores, bolígrafos, válvulas de lastre, cerraduras y velas. Estos representan aproximadamente 9.5\% del PIB (Milenio, 2008; Universopyme, 2008).

Este esquema de impuestos compensatorios terminó el 11 de diciembre de 2011. Desde entonces, México les aplica a los productos chinos la Ley de los Impuesto Generales de Importación y Exportación (TIGIE), la cual establece los aranceles sobre los productos de los países con los que México no tiene firmado ningún tratado o acuerdo comercial (México Business Blog, 2011). La siguiente tabla muestra un ejemplo de cómo quedaron los aranceles a los productos más sensibles para México.

\section{Tabla 9}

Cuotas compensatorias de México a 2011 e impuestos generales del programa de impuestos (TIGIE) a la importación y exportación general a productos chinos seleccionados

\begin{tabular}{llcc}
\hline HTS código & Tipo de producto & $\begin{array}{c}\text { 2011 Cuotas } \\
\text { compensatorias }\end{array}$ & $\begin{array}{c}\text { TIGIE cuotas desde } \\
\text { nov. 12, 2011 }\end{array}$ \\
\hline 6402.20 .01 & Calzado & $70 \%$ & $30 \%$ \\
6402.99 .01 & Sandalias & $70 \%$ & $30 \%$ \\
6106.10 .01 & Camisas deportivas & $80 \%$ & $30 \%$ \\
6204.62 .01 & Pantalones & $80 \%$ & $30 \%$ \\
8504.10 .01 & Componentes de iluminación & $129 \%$ & $5 \%$ \\
8509.40 .01 & Mezcladoras de alimentos & $65 \%$ & $20 \%$ \\
8509.40 .02 & Exprimidores & $65 \%$ & $0 \%$ \\
8516.31 .01 & Secadoras de cabello & $65 \%$ & $15 \%$ \\
8712.00 .02 & Bicicletas para niños & $65 \%$ & $15 \%$ \\
\hline
\end{tabular}

Fuente: Diario Oficial de la Federación, Secretaría de Economía.

Además, de acuerdo con la reglas de la OMC, México puede demandar a China ante ese organismo e imponer nuevos aranceles si demuestra afectaciones a sus sectores productivos. Específicamente, el gobierno de México puede imponer "medida de salvaguardia provisional" 20 días después del lanzamiento de una investigación sobre las importaciones chinas si "surgen circunstancias críticas". El gobierno también ha simplificado los requisitos para poner en marcha una investigación sobre prácticas desleales de comercio (Latin American Herald Tribune, 2011). 
La base jurídica sobre la que México ha establecido restricciones no arancelarias a los productos chinos es que México no considera a China como economía de mercado, no obstante que China se considere a sí misma como tal, aunque con "características chinas". Sin embargo, existen numerosos indicios de que China sigue siendo una economía dirigida.

El gobierno posee y controla la oferta y los precios de los recursos naturales y servicios públicos; controla los bancos y los seguros, presta dinero a través de los bancos de acuerdo con las políticas gubernamentales y las tasas, los controles de la moneda y su valor. Los sectores económicos más importantes, como la producción de acero, están dominados - cuando no totalmente controlados- por las empresas estatales. A través del control de los recursos financieros y el control de precios, el gobierno dicta la oferta y la demanda de los productos y servicios más importantes (Feldman, 2010).

\section{Conclusiones}

Los procesos de liberalización en México y China fueron casi simultáneos. Sin embargo, dichos procesos presentan diferentes aspectos, producto de su situación política y económica. Las relaciones comerciales directas entre México y la República Popular China se iniciaron en la década de 1970 con el intercambio esporádico y en pequeños volúmenes. El auge actual del comercio entre los dos países arrancó en los años ochenta y fue el resultado del cambio en la política comercial de China y México, al integrarse ambos países al proceso de liberalización económica y apertura comercial. En este nuevo contexto de intercambio global, las relaciones de México y China han ido mucho más allá de una relación bilateral, puesto que incluye la producción y las relaciones triangulares con y dentro de América del Norte (en especial con EU), el intercambio con países y regiones de Asia y con la economía mundial en su conjunto. Asimismo, considera los compromisos globales definidos por los organismos internacionales y la lógica de la nueva división internacional del trabajo.

Por otra parte, el creciente papel de las empresas extranjeras y el capital internacional en los segmentos clave de la economía de ambos países se refleja en su integración a las cadenas globales de producción. Desde los años ochenta, la lógica y los intereses de las grandes empresas ha desempeñado un papel importante en la dinámica de la producción en ambos países. Por 
lo tanto, la relación comercial bilateral ha sido influida por la dinámica de la globalización.

La relación comercial entre México y China (y, en consecuencia, las relaciones de producción) es compleja y difícil. En México existe la preocupación en los sectores productivos sobre el papel de China en el comercio mundial y especialmente sobre la relación comercial entre los dos países. Después de la apertura unilateral e incondicional de la economía mexicana, los sectores productivos han estado presionando al gobierno para preservar ciertas áreas del mercado interno. Esta presión se ha traducido en políticas proteccionistas y rechazo a la negociación de nuevos tratados preferenciales de comercio e inversión, ya sea con países de Asia, América Latina u Oceanía.

Con la eliminación de las medidas compensatorias al comercio con China, México se ha comprometido plenamente con las normas de la OMC, pero en el mismo contexto seguirá tratando de proteger el sector clave de su economía contra las importaciones chinas. Es necesario tener en cuenta que México no tiene materias primas para ofrecer al mercado chino, como sí es el caso de otros países de América Latina. Buscar nuevos caminos para una verdadera relación de beneficio mutuo para las dos naciones es una necesidad ineludible. Ambos países deben encontrar nuevas fórmulas de cooperación, incluyendo el comercio bilateral y las relaciones comerciales con el resto del mundo

Como se ha visto a lo largo de este trabajo, en el sentido clásico del concepto económico, México y China son economías competitivas que luchan por una mayor cuota de un mercado para vender o comprar bienes y servicios. Sin embargo, también es claro que hay oportunidades de complementación productiva y de comercialización.

El principal reto para México es el rediseño de su política interna para impulsar reformas destinadas a incrementar la competitividad. Los bajos costos laborales no determinan la ventaja competitiva, al menos en el mediano plazo. La proximidad a los Estados Unidos es un activo estratégico importante, pero la mejora de la eficiencia es claramente una prioridad. ny

\section{Bibliografía}

Baldwin, R. (2006), Managing the Noodle Bowl: The Fragility of East Asian Regionalism, Centre for Economic Policy Research Discussion Paper Series núm. 5561, Ginebra, Centre for Economic Policy Research. 
Baru, S., "Manufacturing Superpower", Business Standard, 2011. Disponible en: http://wap.business-standard.com/storypage. php?id=0\&autono=429174. Fecha de consulta: 21 de marzo de 2011.

Blázquez-Lidoy, J., J. Rodríguez, J. Santiso (2005), “Angel or Devil? Chinese Trade Impact on Latin American Emerging Markets". Ponencia presentada en Annual Bank Conference on Development Economics, Amsterdam, mayo. Disponible en: http://www.oecd.org/dataoecd/24/3/37054336. pdf. Fecha de consulta: 29 de agosto de 2011.

Caporaso, J. David P. (1992), Theories of Political Economy, Cambridge, Reino Unido: Cambridge University Press.

Cornejo, R. (2010), "México y China: diplomacia, competencia económica y percepciones", en Garza, Elizondo Humberto (ed.), Paradigmas y paradojas de la política exterior de México: 2000-2006, México, DF: El Colegio de México, pp. 347-368.

Chinability (2010), "FDI inflows into China 1984-2009”. Disponible en: http:// www.chinability.com/FDI.htm. Fecha de consulta: 03 de abril de 2011.

China Economy.Net (2011), "China's foreign trade towards balance", ChinaEconomy. Disponible en: http://en.ce.cn/Business/Macro-economic/201101/11/t20110111_ 22130490.shtml. Fecha de consulta: 12 de marzo de 2011.

Dent, C. (2007), East Asian Regionalism, Nueva York: Routledge.

Dussel, P. (2005), "The implications of China's entry into the WTO for Mexico", Global Issue Papers, núm. 24. Berlín: Heinrich Böll Foundation.

Dussel, P. (2005b) "The case of trade statistics between China and Mexico to begin bilateral deal with the ignorance”, Economics Report, núm. 335, julioagosto, pp. 50-61.

El Economista, "G-20 Debate en China sobre flujos de capital”. Disponible en: http://media.eleconomista.com.mx/publicaciones_pdf/econo_global/ book/201103/300311a. Fecha de consulta: 30 de marzo de 2011.

Falck, Reyes Melba, J. León-Manríquez (2010), “Mexico’s East Asia strategy”, en Dosch, Jörn y Jacob, Olaf (ed.), Asia and Latin America. Political, economic and multilateral relations, Nueva York: Routledge.

Faust, Jörg y U. Franke (2005), "Relation between Mexico and East Asia", en Faust, Jörg, Mols, Manfred y Kim, Won-Ho (ed.), Latin America and East Asia. Attempts at Diversification. New Patterns of Power, Interest and Cooperation, Müster, Lit Verlag. 
Feldman, Elliot J. (2010), “China’s Status as a Non-Market Economy”, China-US Trade Low. Disponible en: http://www.chinaustradelawblog.com/. Fecha de consulta: 06 de marzo de 2011.

Nowak-Lehmann, Felicitas D., S. Vollmer, I. Martinez-Zarzoso, "Competitiveness. A Comparison of China and Mexico", Paper provided by CESifo Group Munich in its series CESifo Working Paper Series, number 2111, 2007. Disponible en: http://www.cesifo.de/DocCIDL/cesifo1_wp2111. pdf. Fecha de consulta: 14 de marzo de 2011.

Feuerweker, A. (1996), The Chinese Economy, 1870-1949. An Arbor: University of Michigan Press.

Felkins L. (1997), "Introduction to Public Choice Theory". Disponible en: http://perspicuity.net/sd/pub-choice.html. Fecha de consulta: 16 de marzo de 2011.

Fieden, J., D. Lake A. (1999, 4ª edición), International Political Economy. Perspectives on Global Power and Wealth, Londres y Nueva York: Routledge.

Flynn, D. O., L. Frost, A. J. H. Latham (1999), "Introduction: Pacific Centuries Emerging". Pacific Centuries. Pacific and Pacific and Pacific Rim History since the Sixteenth Century, Londres y Nueva York: Routledge, pp. 1-22.

Gallagher, K. (2008), “Competing for America's business”, The Guardian. Disponible en: http://www.guardian.co.uk/commentisfree/2008/sep/03/ useconomy.mexico. Fecha de consulta: 18 de marzo de 2011.

Gallagher, K. (2011), "China Discovers Latin America”, Berkeley Review of Latin American Studies. Disponible en: http://www.ase.tufts.edu/gdae/Pubs/rp/ GallagherBRLASFall2011.pdf. Fecha de consulta: 21 de marzo de 2011. Gilpin, R. (1996), "The Nature of Political Economy", Art, J. Robert y Jervis Robert, International Politics. Enduring Concepts and Contemporary Issue, Nueva York: Harper Collins College Publishers, pp. 269-285.

Gutiérrez, A., "China's Economic Invasion in to Mexico: A Threat to the US or an Opportunity for Mexico?", Council on Hemispheric Affairs, 1995. Disponible en: http://www.coha.org/china\%E2\%80\%99s-economicinvasion-into-mexico-a-threat-to-the-us-or-an-opportunity-for-mexico/. Fecha de consulta: 18 de marzo de 2011.

Hearn, A. (2010), "México y China: amenazas, oportunidades y el impacto de la cultura”, en Dueñas, A. y Prudnikov, V. (coord.), La Cuenca del Pacífico: alternativa para la política exterior de México, México: Impresora Múltiple, pp. 73-87.

Hernández, R. (2003), "El comercio exterior de China a principios del siglo xxi”, México y la Cuenca del Pacífico, vol. 6, núm. 20, pp. 57-69. 
IHS (2011), “China Set to Take the Lead in Global Manufacturing”, IHS Global Insight. Disponible en: www.ihsglobalinsight.com. Fecha de consulta: 20 de marzo de 2011.

Jenkins, R. y E. Dussel Peters (eds.) (2009), China and Latin America. Economic relations in the twenty-first century, Bonn-México: Deutsches Institut für Entwicklungspolitik gGmbH y Universidad Nacional Autónoma de México (UNAM).

Jiang, S. (2008), “The Chinese Foreign Policy Perspective”, en Roett, R. y Paz, G. (eds.), China's Expansion into the Western Hemisphere. Implications for Latin America and the United States, Brookings Institution Press, Washington, pp. 27- 43.

Keohane R. (1982), “The Demand for International Regimes”, International Organization, vol. 36, núm. 2, primavera.

Keohane R. (1984), After Hegemony: Cooperation and Discord in the Wold Political Economy, Princeton University Press, Princeton, caps. II y III.

Krasner, S. (1999), "State Power and the Structure of International Trade", Frieden, J. (contributor); Lake, D. (contributor), International Political Economy, Londres: Routledge, pp. 19-36.

Latin American Herald Tribune (2011), "Mexico Poised to Restrict Import of Chinese Footwear", 8 de septiembre. Disponible en: <http://www.laht.com/article.asp?ArticleId=423566\&C ategoryId=14091. Fecha de consulta: 05 de noviembre de 2011. Lenz, A. (2003), China's World Trade and Investment: an Overview. UsChina Economic and Security Review Commission. Disponible en: http:// www.uscc.gov/researchpapers/2000_2003/reports/03_oct_drallenlenz. htm. Fecha de consulta: 12 de marzo de 2011.

Li, M. (2007), The political economy of trade relations between the United States and People's Republic of China. A dissertation submitted to the Graduate Faculty of George Mason University in partial fulfilment of the requirements for the degree of Doctor of Philosophy Economics.

Maddison, A. (2007), Chinese Economic Performance in the Long Run, OECD Development Centre Studies, segunda edición revisada y actualizada 960-2030 AD, p. 18.

Mexico Business Blog (2011), "Duties on Chinese imports to drop in December”. Disponible en: http://bdp-americas.com/blog/2011/09/26/ duties-on-chinese-imports-to-drop-in-december. Fecha de consulta: 05 de noviembre de 2011. 
Martínez, José Luis (1984), Pasajeros de Indias, Alianza Editorial Mexicana, México.

MFA (2010), "China and México. Bilateral relations", Ministry of Foreign Affairs of the People's Republic of China. Disponible en: http://www.mfa. gov.cn/eng/wjb/zzjg/ldmzs/gjlb/3508/t17382.htm. Fecha de consulta: 20 de marzo de 2011.

Middlebrook, J. Kevin y E. Zepeda (2003), "On the Political Economy of Mexican Development Policy”, en Middlebrook, J. Kevin y Zepeda, E. (eds.), Confronting Development: assessing Mexico's economic and social policy challenges, Stanford: Stanford University Press.

Milenio (2008), "Acuerdan México y China fin a cuotas compensatorias en 2012", MilenioOnline. Disponible en: http://impreso.milenio.com/ node/8068345. Fecha de consulta: 06 de marzo de 2011.

Moran, T. (2011), "Foreign direct investment in China: trading competitiveness for access?", East Asia Forum. Disponible en: http://www.eastasiaforum.org/2011/04/11/foreign-direct-investment-in-china-tradingcompetitiveness-for-access. Fecha de consulta: 20 de abril de 2011.

Nájar, A. (2010), "China-México: una compleja y antigua relación”, BBC Mundo, México. Disponible en: http://www.bbc.co.uk/mundo/noticias/2010/12/101230_mexico_china_pirateria_an.shtml. Fecha de consulta: 31 de diciembre de 2010.

People's Daily Online (2011), "China's foreign trade structure diversified", enero 12. Disponible en: http://english.peopledaily.com. cn/90001/90778/7258000.html. Fecha de consulta: 18 de abril de 2011.

Pettit, P. (1996), "Institutional Design and Rational Choice", en Goodin, R. (edit.). The Theory of Institutional Design, Cambridge: Cambridge University Press, pp. 54-72.

Prasad, E. (2004), China's Growth and Integration into the World Economy. Prospects and Challenges, International Monetary Fund, Washington, p. 1.

ProMéxico (2010a), "Síntesis de la Relación Comercial México-China". Unidad de Inteligencia de Negocios. Unidad de Inteligencia de Negocios. Disponible en: http://www.promexico.gob.mx/work/sites/Promexico/ resources/LocalContent/2221/2/nb_china.pdf. Fecha de consulta: 22 de octubre de 2010.

ProMéxico (2010b). Disponible en: http://www.promexico.gob.mx. Fecha de consulta: 20 de abril de 2011. 
Rashid, F. (2011), “China tops in manufacturing output in world”, The Financial Express, 14 de marzo. Disponible en: http://thefinancialexpress-bd. com/more.php?news_id=129271\&date=2011-03-15. Fecha de consulta: 21 de marzo de 2011.

Rumbaugh, T. y Blancher, N. (2004), China: International Trade and WTO Accession, IMF Working Paper, Washington (WP/04/36).

Roett, R. (2010), “China's deepening ties with Latin America. A work in progress”, Breslin, Shaun (ed.), Handbook or China's International Relations, Londres: Routledge, pp. 200-208.

Roett, R. Guadalupe y Paz (eds.) (2008), China's Expansion into the Western Hemisphere. Implications for Latin America and the United States, Brookings Institution Press, Washington.

Santiago Cruz, F. (1962), La Nao de China, México: Editorial Jus.

-— (1998), El Galeón de Acapulco, siglos XVI al XIX, México: INAH.

- - (1997), El Galeón de Manila. Un mar de historias, México: JGH Editores.

Smithers, S. Rueda (1998), "La Nao de China, riqueza a contracorriente", Arqueología mexicana, vol. vi, núm. 33, septiembre-octubre.

Universopyme, "Firman acuerdo cuotas compensatorias México y China", Universopyme. Disponible en: http://www.universopyme.com.mx/index. php?option=com_content\&task=view\&id=2229\&Itemid=136. Fecha de consulta: 06 de marzo de 2011.

Villarreal, A. (2010), "Mexico's Free Trade Agreements", CRS Report for Congress. Congressional Research Service 7-5700. Disponible en: www.crs.gov. Wu, M. (2011), “China' Currency Isn't Our Problem”, New York Times, 18 de enero, p. A25. Disponible en: http://www.nytimes.com/2011/01/18/ opinion/18wu.html?_r=1. Fecha de consulta: 27 de marzo de 2011.

Yue, Y. (2009), China \& Mexico: Comparison of Trade Competitiveness. Institute of Latin American Studies at the Chinese Academy of Social Sciences.

World Economic Outlook (2011). International Monetary Fund. Disponible en: http://www.imf.org/external/pubs/ft/weo/2011/02/weodata/ weorept.aspx? sy=2011\&ey=2016\&scsm $=1 \&$ ssd $=1 \&$ sort $=$ country\&ds $=$. $\& b r=1 \& c=924 \& s=N G D P D \% 2 C N G D P D P C \% 2 C P P P G D P \% 2 C P P P P C \% 2 C$ BCA_NGDPD\&grp=0\&a=\&pr.x=83\&pr.y=18. Fecha de consulta: 04 de febrero de 2012.

Zha, D. y S. Breslin (2010), "Oiling the wheels of foreign policy? Energy security and China's international relations", in Breslin, Shaun (edit.) Handbook or China's International Relations, Londres: Routledge, pp. 64-75. 


\section{Migración japonesa a \\ Guadalajara en el siglo XVII}

Melba Falck Reyes

Héctor Palacios

El japonés que conquistó Guadalajara

La historia de Juan de Páez

en la Guadalajara del siglo XvII
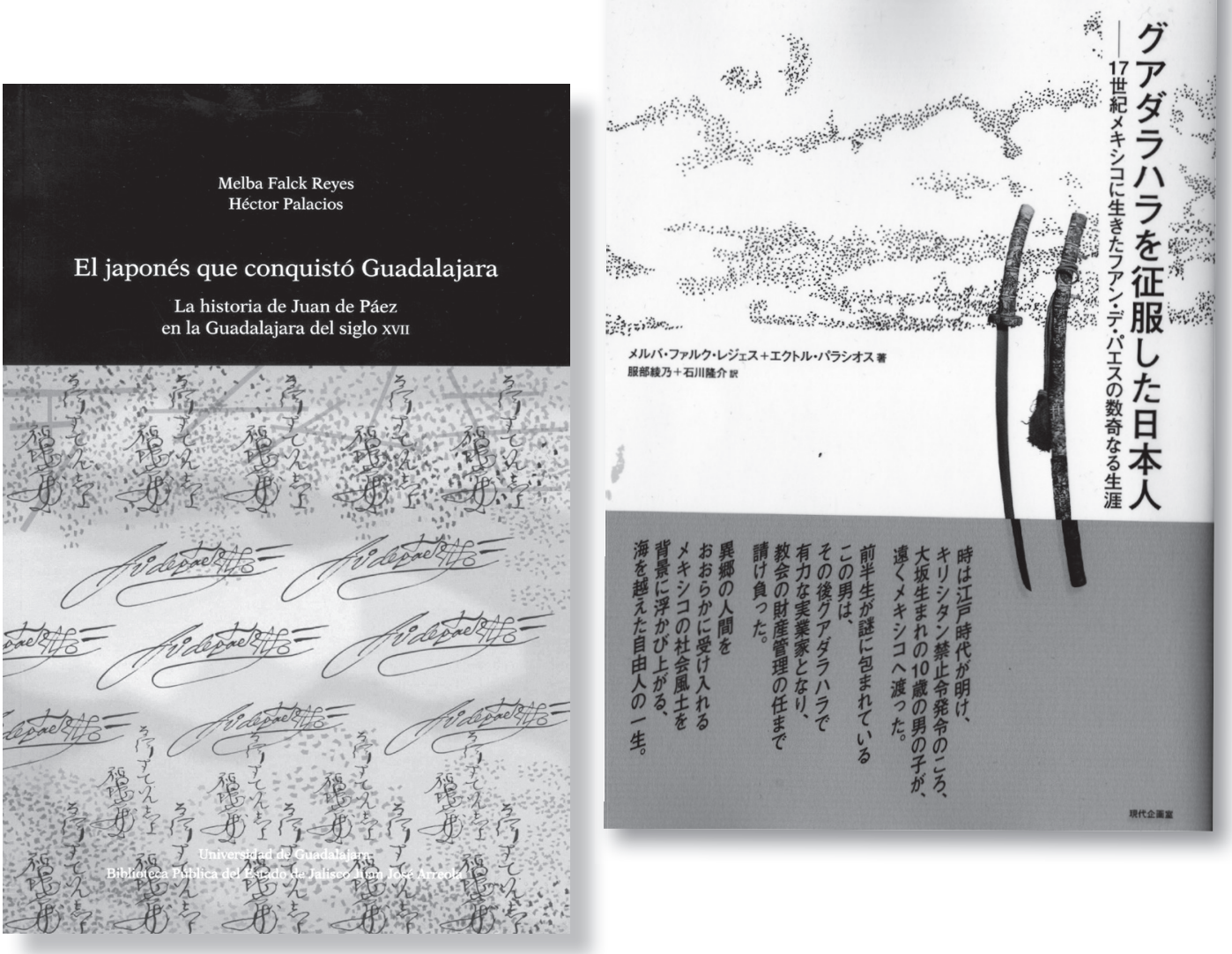

El japonés que conquistó Guadalajara. La historia de Juan de Páez en la Guadalajara del siglo XVII, de Melba Falck Reyes y Héctor Palacios fue traducido al japonés y publicado en Japón por la Editorial Gendai Kikakushitsu en diciembre de 2010. Traducido por: Ayano Hattori y Juan Tyusuke Ishikawa. La edición en japonés contó con el apoyo del Programa de Apoyo a la taducción de obras mexicanas en lenguas extranjeras (Protrad) y el Fideicomiso "Fondo de la Amistad México-Japón". 